\title{
SEPTIC ARTHRITIS OF THE HIP IN ADULTS: A RARE PRESENTATION
}

\author{
Kuppa Srinivas ${ }^{1}$, Yerukala Ramana², Dema Rajaiah ${ }^{3}$, Sujith Omkaram4, S. Venkateswar Reddy ${ }^{5}$
}

\section{HOW TO CITE THIS ARTICLE:}

Kuppa Srinivas, Yerukala Ramana, Dema Rajaiah, Sujith Omkaram, S. Venkateswar Reddy. "Septic Arthritis of the Hip in Adults: A Rare Presentation". Journal of Evolution of Medical and Dental Sciences 2015; Vol. 4, Issue 08, January 26; Page: 1377-1380, DOI: 10.14260/jemds/2015/192

\begin{abstract}
Septic Arthritis also known as infectious arthritis, can be bacterial or fungal arthritis. The condition is an inflammation of a joint that is caused by an infection. Typically, Septic Arthritis affects one large joint in the body such as knee or hip. Generally, Septic Arthritis is present with complete absorption of the head of the Femur in infants. A case was encountered in which the complete absorption of the femoral head was seen in adults also.
\end{abstract}

KEYWORDS: Septic arthritis of hip, adults, absorption of head.

INTRODUCTION: Septic Arthritis of hip in adults is generally present with high grade fever with severe limitations of hip joint movement. The X-Ray of the Pelvis of both the hip joints in Septic Arthritis of hip in adults shows destruction of articular cartilage and narrowing of joint space and destruction of adjoining bone. But we had a case where there was a complete absorption of head of Femur with the destruction of articular surface of Acetabulum, which is more commonly seen in Septic Arthritis of hip in infants.

CLINICAL HISTORY: A female patient aged about 40 years c/o high grade fever with multiple joints pain was admitted in the medical ward. The patient was investigated for all types of viral fever and other causes of fever. The patient was on IV antibiotics and analgesics with $10 \mathrm{mg}$ of Prednisilone twice a day. The patient c/o severe pain in the left hip joint and hence, referred to the Orthopaedic Dept. O/E, the patient was having high grade fever for the past 15 days. There was no history of injury. The patient was having multiple joint pains more on the hip joint. O/E, the hip joint was kept in 40 degrees of fixed flexion deformity with severe restriction of movements of hip joint. X-ray of pelvis with both hip joints - AP view was taken. X-ray showed that there is complete destruction of femoral head with narrowing of joint space. The patient was provisionally diagnosed as Septic Arthritis of the hip and transferred to the Orthopaedics department.

\section{INVESTIGATIONS:}

- $\mathrm{Hb}$

- ESR

- TC

- RA factor

- CRP

- Blood Sugar (random)

- Blood urea

- Serum Creatinine

- Mantoux test

- HIV

- HBSAG and HCV
- 7 gms.

- $100 \mathrm{~mm}\left(1^{\text {st }}\right.$ Hour$)$.

- 80000 Cells (with raised polymorph cells).

- Negative.

- Positive.

- $125 \mathrm{mg}$.

- $32 \mathrm{mg}$.

- $1.2 \mathrm{mg}$.

- Negative.

- Non reactive.

- Negative. 


\section{CASE REPORT}

TREATMENT: Skin traction was applied and IV antibiotics were started. Anaemia was corrected with blood transfusions. Hip joint aspiration was done. About 20cc pus was aspirated and sent for culture and sensitivity. Culture is positive for staphylococcus aureus and sensitive for piperacillin and tazobactum. Anaemia was corrected, but there was no improvement of fever and pain with antibiotics and analgesics and so Arthrotomy and joint debridement was planned. Prednisolone was tapered and stopped before the surgery. Under spinal anaesthesia we did Arthrotomy through the posterior approach. Once we opened the capsule of hip joint, about 300cc pus was drained out. But head of the femur was completely absent.

We could see only small remnants of the head. The joint was thoroughly washed with $\mathrm{H}_{2} \mathrm{O}_{2}$, Saline and Betadine. The articular surface of Acetabulum was inspected. The destruction of articular surface was noted. The joint was thoroughly debrided and the remaining small part of Calcar of the neck of Femur was removed. The wound was closed in layers after keeping a suction drain tube. Upper Tibial pin traction was applied. The remnants of the head and capsule were sent for histopathological examination. IV antibiotics and analgesics were given. Within $72 \mathrm{hrs}$ the fever was controlled and the pain in the hip joint also reduced significantly. After 2 weeks, the sutures were removed. The patient was discharged after 4 weeks.

DISCUSSION: Septic arthritis is the infection of a joint that may be caused by bacteria, virus or fungi. The risk of developing Septic Arthritis includes taking immunosuppressive drugs, intravenous drug abuse, past joint disease, injury or surgery, underlying medical disease including diabetes, alcoholism, sickle cell anaemia, rheumatic disease and immunodeficiency disorders. ${ }^{1,2}$ The symptoms include high fever with chills as well as joint pain, swelling, redness and warmth. Clinically there will be severe painful restriction of all movements. Radiologically in the initial stages, joint effusion will be seen. Later there will be a destruction of joint space and further destruction of adjacent bones. ${ }^{3}$

But in Septic Arthritis hip in infants, we can see complete destruction of head (Tom Smith Arthritis).Usually complete destruction of head will not be seen in Septic Arthritis of hip in adults. The differential diagnosis of Septic Arthritis of adults include rheumatoid arthritis, osteonecrosis of the femoral head, neuropathic arthropathy of the hip, malignancy, seronegative arthropathy, and rapidly destructive osteoarthropathy of the hip joint. The radiographic presentation of hip sepsis can be very similar to that of rapidly destructive osteoarthropathy of the hip. Aspiration of hip joint may give evidence of infection if pus is there. But in this case, with no predisposing factor, the patient developed Septic Arthritis of the hip with complete resorption of the head.

CONCLUSION: Normally in Septic Arthritis of hip in adults may present with destruction of joint space with destruction of adjoining bone. In Septic Arthritis of hip in infancy, we can see complete destruction of head of Femur. In this patient, we can see unusual complete absorption of head of femur without any predisposing factors like immunosuppressive drugs, diabetes mellitus, rheumatoid arthritis etc.

\section{REFERENCES:}

1. Bulmer JH. Septic arthritis of the hip in adults. J Bone Joint Surg Br 1966; 48: 289-98.

2. Ryn KN, Kim EJ, Ischemic necrosis of the entire femoral head and rapidly destructive hip disease: potential causative relationship, 1997 Mar, 26 (3): 143-9. 


\section{CASE REPORT}

3. Bock GW, Garcia A, Rapidly destructive hip disease: clinical and imaging abnormalities, Feb 1993, 186 (2): 461-6.

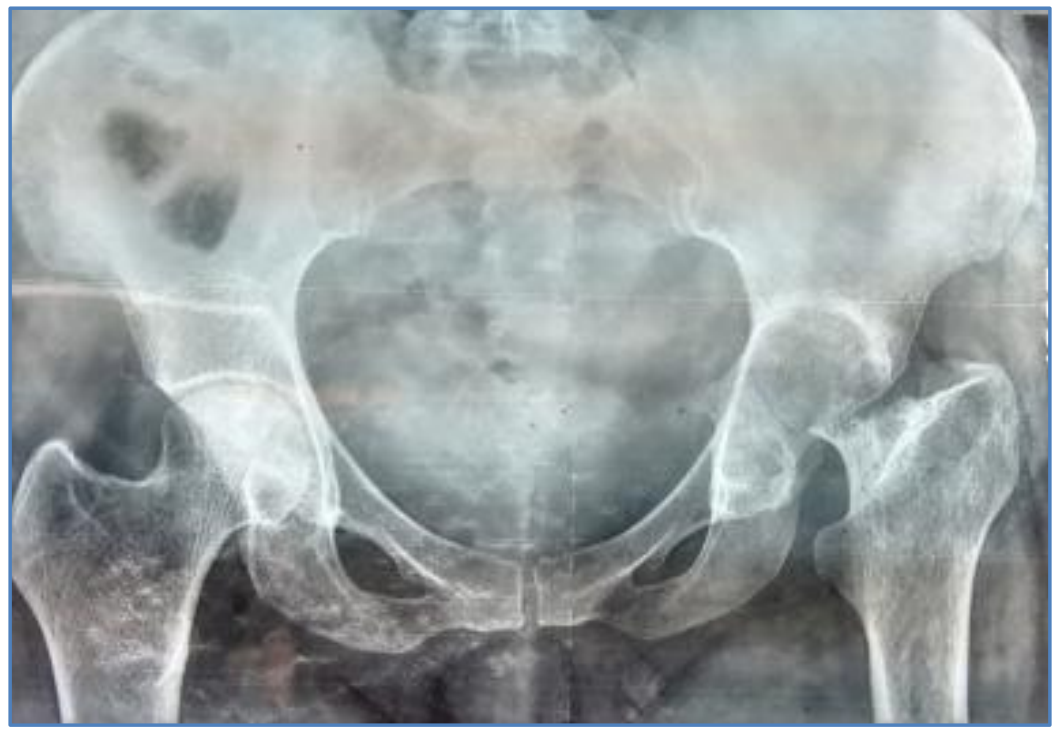

Fig. 1: preoperative radiograph showing complete resorption of femoral head on left side

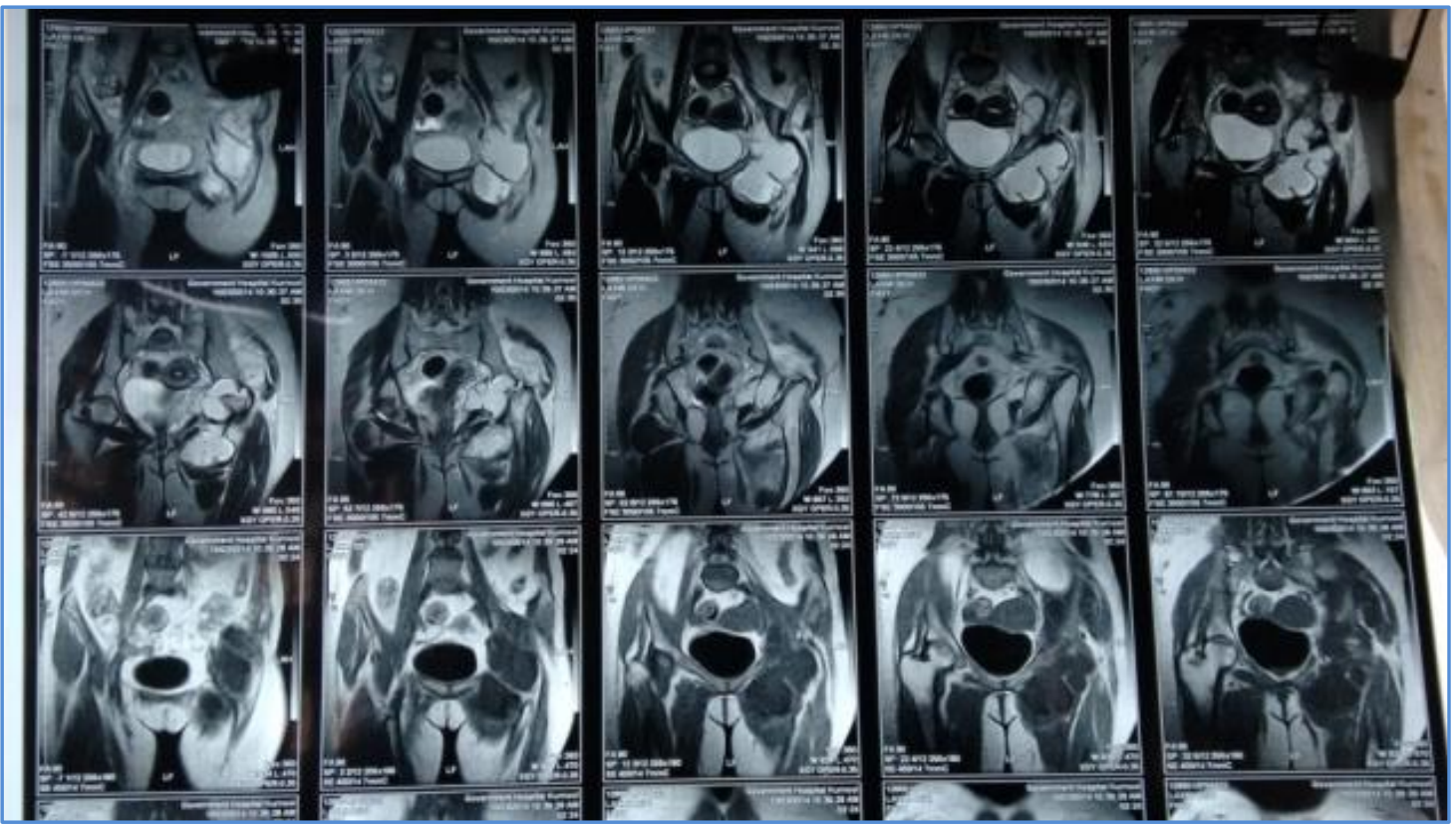

Fig. 2: MRI pelvis showing abscess in left hip joint with complete absorption of femoral head and superior migration of greater trochanter 


\section{CASE REPORT}

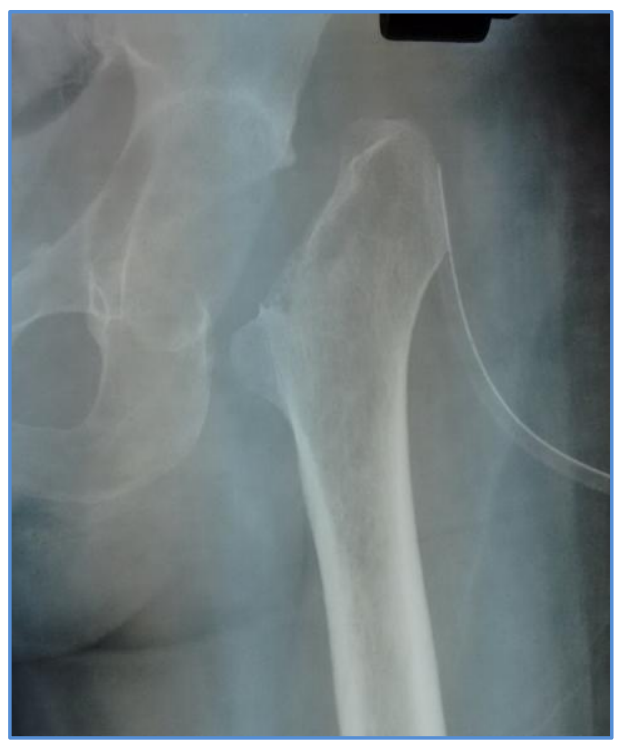

Fig. 3: Post-operative radiograph showing status of hip after girdlestone resection arthroplasty and debridement

\section{AUTHORS:}

1. Kuppa Srinivas

2. Yerukala Ramana

3. Dema Rajaiah

4. Sujith Omkaram

5. S. Venkateswar Reddy

\section{PARTICULARS OF CONTRIBUTORS:}

1. I/C Professor, Department of Orthopaedics, Kurnool Medical College, Kurnool, Andhra Pradesh.

2. Assistant Professor, Department of Orthopaedics, Kurnool Medical College, Kurnool, Andhra Pradesh.

3. Assistant Professor, Department of Orthopaedics, Kurnool Medical College, Kurnool, Andhra Pradesh.
4. Post Graduate, Department of Orthopaedics, Kurnool Medical College, Kurnool, Andhra Pradesh.

5. Post Graduate, Department of Orthopaedics, Kurnool Medical College, Kurnool, Andhra Pradesh.

\section{NAME ADDRESS EMAIL ID OF THE CORRESPONDING AUTHOR:}

Dr. Kuppa Srinivas, \# 50-760-A-109,

Gayathri Estates, Kurnool, Andhra Pradesh-518002.

E-mail: drsrinivasmsortho@gmail.com

Date of Submission: 30/12/2014.

Date of Peer Review: 31/12/2014.

Date of Acceptance: 16/01/2015.

Date of Publishing: 24/01/2015. 